\title{
From Complex Inorganic Oxides to Ag-Bi Nanoalloy: Synthesis by Femtosecond Laser Irradiation
}

Thales R. Machado, ${ }^{\dagger}$ Nadia G. Macedo, ${ }^{\dagger}$ Marcelo Assis, ${ }^{\dagger}{ }^{\oplus}$ Carlos Donate-Buendia, ${ }^{\ddagger}$ Gladys Mínguez-Vega, ${ }^{\dagger}$ Mayara M. Teixeira, ${ }^{\dagger}$ Camila C. Foggi, ${ }^{\dagger \oplus}$ Carlos E. Vergani, ${ }^{\perp}$ Héctor Beltrán-Mir, ${ }^{, \odot}$ Juan Andrés, ${ }^{\| \odot ~ E l o i s a ~ C o r d o n c i l l o, ~}{ }^{8}$ and Elson Longo, ${ }^{*}, \odot$

${ }^{\dagger}$ Departamento de Química, CDMF, Universidade Federal de São Carlos (UFSCar), São Carlos 13565-905, São Paulo, Brazil

${ }^{\ddagger}$ Institut de Noves Tecnologies de la Imatge (INIT), GROC, ${ }^{\S}$ Departament de Química Inorgànica i Orgànica, and "Departament de Química Física i Analítica, Universitat Jaume I (UJI), Castellón de la Plana 12071, Castelló, Spain

${ }^{\perp}$ Faculdade de Odontologia, Universidade Estadual Paulista (UNESP), Araraquara 14801-385, São Paulo, Brazil

Supporting Information

\begin{abstract}
Bimetallic nanoalloys with a wide variety of structures and compositions have been fabricated through many diverse techniques. Generally, various steps and chemicals are involved in their fabrication. In this study, the synthesis of $\mathrm{Ag}-\mathrm{Bi}$ nanoalloys by femtosecond laser irradiation of an inorganic oxide $\mathrm{Ag}_{2} \mathrm{WO}_{4} / \mathrm{NaBiO}_{3}$ target without any chemicals like reducing agents or solvent is presented. The interaction between these materials and the ultrashort pulse of light allows the migration of $\mathrm{Ag}$ and $\mathrm{Bi}$
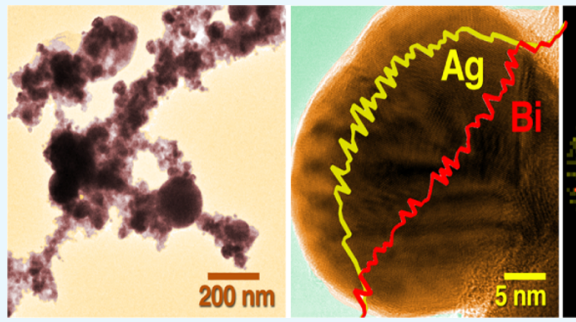

$\mathrm{Ag}$ atoms from the crystal lattice to the particles surfaces and then to the plasma plume, where the reduction of the positively charged $\mathrm{Ag}$ and Bi species in their respective metallic species takes place. Subsequently, the controlled nucleation and growth of the $\mathrm{Ag}-\mathrm{Bi}$ alloyed nanoparticles occurs in situ during the irradiation process in air. Although at the bulk level, these elements are highly immiscible, it was experimentally demonstrated that at nanoscale, the $\mathrm{Ag}-\mathrm{Bi}$ nanoalloy can assume a randomly mixed structure with up to $6 \pm 1$ atom \% of Bi solubilized into the face-centered cubic structure of Ag. Furthermore, the Ag-Bi binary system possesses high antibacterial activity against Staphylococcus aureus (methicillin-resistant and methicilin-susceptible), which is interesting for potential antimicrobial applications, consequently increasing their range of applicability. The present results provide potential insights into the structures formed by the $\mathrm{Ag}-\mathrm{Bi}$ systems at the nanoscale and reveal a new processing method where complex inorganic oxides can be used as precursors for the controlled synthesis of alloyed bimetallic nanoparticles.
\end{abstract}

\section{INTRODUCTION}

Nanoalloys (NAs) composed of different metals are of broad scientific interest mainly because they combine the properties of single-metal nanoparticles (NPs) and generally present unique properties not found in the NPs of the two metals individually. ${ }^{1,2}$ NAs composed of $\mathrm{Ag}, \mathrm{Au}, \mathrm{Bi}, \mathrm{Co}, \mathrm{Cu}, \mathrm{Ni}, \mathrm{Pd}$, $\mathrm{Pt}, \mathrm{Sb}$, and other metals exhibit new functions because of the synergistic rather than merely additive effects of the two distinct metals, leading to markedly enhanced physical and chemical properties. This fact enables their widespread applications in various fields, such as catalysis, electronics, photonics, and biomedicine. ${ }^{3-16}$ These technological applications are mainly dependent on the chemical composition, morphology, and size of the NAs. ${ }^{2,17}$ Moreover, the properties of bimetallic NAs also depend on their complex structures, in which the atomic arrangements can be classified into four mixing patterns: core-shell, multishell, and subcluster ("Janus" particles) segregated patterns or a mixed structure (ordered or a randomly mixed solid solution). ${ }^{18}$

Although the goal of obtaining bimetallic NAs is very attractive, it has been proven to be difficult to achieve when two immiscible metals are targeted. However, two elements which do not have a significant miscibility gap in their phase diagram at the bulk level can form alloys at the nanoscale. ${ }^{19-21}$ $\mathrm{Ag}-\mathrm{Bi} \mathrm{NA}$ is a clear example. The very low solubility between $\mathrm{Ag}$ and $\mathrm{Bi}$ elements, with less than $\sim 3$ atom $\%$ of $\mathrm{Bi}$ solubilizing in $\mathrm{Ag}$ matrix (solid solution) and no detectable solubility of $\mathrm{Ag}$ in $\mathrm{Bi}$ in the bulk scale, ${ }^{22,23}$ is due to their different crystalline structures, i.e., face-centered cubic (fcc) for $\mathrm{Ag}^{0}(\mathrm{fm} 3 \mathrm{~m})$ and rhombohedral for $\mathrm{Bi}^{0}(\mathrm{R} 3 \mathrm{~m})$ at atmospheric conditions. ${ }^{24}$ At the nanoscale, Ag-Bi alloyed NPs have been stabilized with coexisting bulklike lattices of $\mathrm{Ag}^{0}$ and $\mathrm{Bi}^{0}$ in the same particle (stack of nanodomains) or a segregated pattern, depending on the synthesis conditions of the soft chemical route (temperature $<200{ }^{\circ} \mathrm{C}$ ). ${ }^{25-27}$ The $\mathrm{Ag}-\mathrm{Bi} \mathrm{NA}$ is an emerging material that has attracted recent interest due to its superior photocatalytic production of $\mathrm{H}_{2}$ via water splitting, ${ }^{25}$ degradation of organic pollutants in wastewater, ${ }^{26}$ and

Received: June 6, 2018

Accepted: August 13, 2018

Published: August 24, 2018 


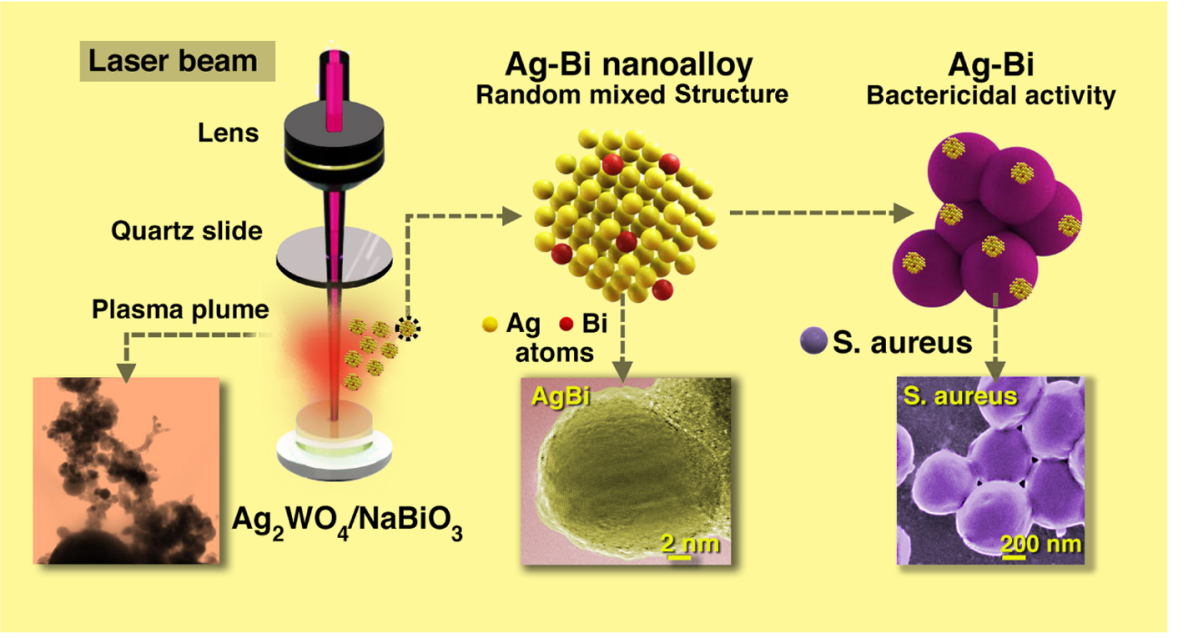

Figure 1. Representation of the procedure employed to obtain $\mathrm{Ag}-\mathrm{Bi}$ NAs by fs laser irradiation on a $\mathrm{Ag}_{2} \mathrm{WO}_{4} / \mathrm{NaBiO}_{3}$ target, where the generation of the plasma plume takes place (left). Irregular spheres of $\mathrm{Ag}-\mathrm{Bi}$ alloyed NPs are sensed (center), presenting a randomly mixed pattern (solid solution) of $\mathrm{Bi}$ atoms in $\mathrm{Ag}$ structure. $\mathrm{Ag}-\mathrm{Bi}$ NAs present high bactericidal activity against Staphylococcus aureus (methicillin-resistant and methicillin-susceptible) (right). The digital micrographs illustrate, from left to right, the plasma plume generated, a single $\mathrm{Ag}-\mathrm{Bi}$ alloyed $\mathrm{NP}$, and an agglomerate of $S$. aureus bacteria.

decomposition of nitric oxide. ${ }^{27}$ However, at present, there are only few published studies investigating other possible structures which can be formed in the $\mathrm{Ag}-\mathrm{Bi}$ system at the nanoscale, such as pure solid solutions of $\mathrm{Ag}$ and $\mathrm{Bi}$ elements, and the potential applications of the resulting NAs.

Due to the extensive proliferation of femtosecond ( $f$ ) laser technology in recent years, the interaction of a molecular system with intense laser light has allowed an increasing number of researchers to investigate the appearance of unusual phenomena, such as melting, ablation, and recrystallization, leading to the stabilization of nonequilibrium or metastable phases with unique compositions, structures, and properties. $^{28-30}$ Irradiation of a mixture of single-element micro/ nanomaterials may lead to their alloying and the fabrication of multielement structures, making this a top-down, efficient, versatile, surfactant-free, and low-cost approach for obtaining bimetallic NAs. ${ }^{31-35}$ Thus, fabrication of NAs by fs laser irradiation can provide a green synthesis solution, in which no organic solvents or chemical reducing agents are needed. ${ }^{36,37}$ However, to the best of our knowledge, there are no studies in the literature reporting the fabrication of $\mathrm{Ag}-\mathrm{Bi}$ NAs by fs laser irradiation.

In this communication we seek to fulfill 2 -fold objectives (Figure 1). The first is to report the novel formation of a AgBi NA with nonconventional structure and composition stabilized at the nanoscale with a random mixture of up to 6 \pm 1 atom \% of $\mathrm{Bi}$ into the fcc structure of $\mathrm{Ag}$ via fs laser irradiation of a $\mathrm{Ag}_{2} \mathrm{WO}_{4} / \mathrm{NaBiO}_{3}$ target. To support this finding, a detailed analysis of images obtained by advanced electron microscopy techniques, including field-emission scanning electron microscopy (FE-SEM), transmission electrons microscopy (TEM), high-resolution TEM (HR-TEM), scanning TEM (STEM), and energy-dispersive X-ray spectroscopy (EDS), has been performed. The second aim is to demonstrate that the as-synthesized $\mathrm{Ag}-\mathrm{Bi} \mathrm{NA}$ has an excellent bactericidal activity and contribute to broadening its possible applications.

\section{RESULTS AND DISCUSSION}

In the last few years, our research group has conducted several studies focused on the growth of monometallic NPs on surfaces of semiconductors for technological and biomedical applications of the resultant composites..$^{35,38-40}$ In this sense, we demonstrated theoretically and experimentally that Agbased complex inorganic oxides are very suitable for the controlled synthesis of $\mathrm{Ag}^{0}$ nanostructures with distinct sizes and shapes by their interaction with an electron beam. ${ }^{35,39-45}$ Recently, we have reported how these structures can also be used as substrate for $\mathrm{Ag}^{0}$ synthesis by fs laser irradiation, while Bi-based oxides can be used for the formation of $\mathrm{Bi}^{0} \mathrm{NPs}{ }^{35,46}$ For the present study, we selected a combined substrate composed of $\mathrm{Ag}_{2} \mathrm{WO}_{4}$ microrods and $\mathrm{NaBiO}_{3}$ nanoflakes as the sources of $\mathrm{Ag}^{0}$ and $\mathrm{Bi}^{0}$ nanoclusters, respectively. Hence, we aim to associate the recent advances of our current research works focused on the study of semiconductor (complex inorganic oxide) interactions with electrons and photons to demonstrate, for the first time, that a $\mathrm{Ag}-\mathrm{Bi} \mathrm{NA}$ can be prepared by fs laser irradiation. For a detailed description of the structural and morphological characteristics of the materials used, refer to Section S1 of the Supporting Information (SI).

The $\mathrm{Ag}_{2} \mathrm{WO}_{4}$ and $\mathrm{NaBiO}_{3}$ materials possess significant lattice disorder, and by interacting with photons, the $\mathrm{Ag}$ and $\mathrm{Bi}$ species migrate from the crystal lattice to the particles surfaces and then to the plasma plume, where the reduction of the positively charged $\mathrm{Ag}$ and $\mathrm{Bi}$ species in their respective metallic species takes place. Since the reduction, nucleation, and growth of the $\mathrm{Ag}^{0}$ and $\mathrm{Bi}^{0}$ metallic structures occur in a controlled manner and in situ with the irradiation process in air, the reaction kinetics are compatible with the experimental conditions necessary for the formation of $\mathrm{Ag}-\mathrm{Bi}$ NAs. Hence, the samples were ablated in air and the Ag-Bi NAs are expected to be formed in the plasma plume generated in the laser-matter interaction. In this plume, electrons and ions of the $\mathrm{Ag}$ and $\mathrm{Bi}$ coexist in extreme pressure and thermal conditions, which favors the formation of the alloy. When the 

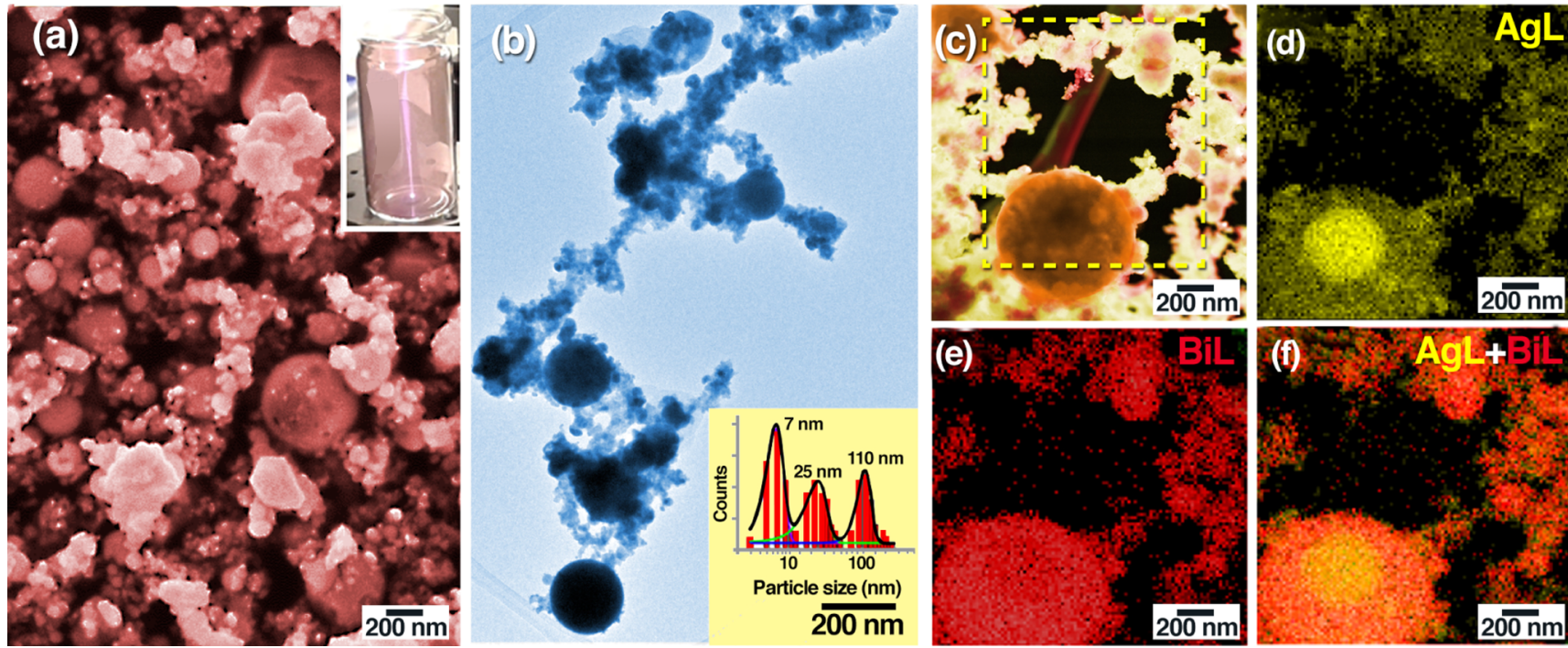

Figure 2. General view of the $\mathrm{Ag}-\mathrm{Bi}$ alloyed NPs produced by fs irradiation: (a) FE-SEM image and a digital image (inset) illustrating the irradiation process of the $\mathrm{Ag}_{2} \mathrm{WO}_{4} / \mathrm{NaBiO}_{3}$ target (bottle bottom) and the generation of $\mathrm{Ag}-\mathrm{Bi}$ NAs (reddish plasma plume), (b) TEM image with an estimation of particle dimensions (inset), (c) BF-STEM image, (d) AgL EDS map, (e) BiL EDS map, and (f) AgL-BiL EDS map overlay evidencing a mixed pattern of these elements.

plasma cools down and disappears, it releases the nanoparticles in the air.

Figure 2a,b shows FE-SEM and TEM images, respectively, of the $\mathrm{Ag}-\mathrm{Bi}$ NPs obtained by fs laser irradiation. As can be seen, spherical nanoparticles are present, which are typically observed in nanomaterials obtained by laser treatment. ${ }^{31,34}$ These nanospheres have average sizes of 7,25 , and $110 \mathrm{~nm}$, as shown Figure 2b (inset). Their composition was qualitatively studied by EDS mapping in the STEM imaging mode, and Figure $2 c$ shows a bright-field STEM image (BF-STEM) of the analyzed region. The elemental distributions of $\mathrm{Ag}$ and $\mathrm{Bi}$ in this specific region are shown in Figure 2d,e, respectively. By overlaying these maps (Figure 2f), homogeneous $\mathrm{Ag}$ and $\mathrm{Bi}$ distributions were observed throughout almost all of the analyzed region, indicating the success of the synthesis procedure in obtaining a mixed $\mathrm{Ag}-\mathrm{Bi}$ pattern. The elemental map also confirms that after fs laser irradiation, some spots in the samples are richer in either Ag (yellow regions) or Bi (red regions), as expected. This is because of the very limited solubility of $\mathrm{Ag}$ in the $\mathrm{Bi}$ crystalline structure and vice versa.

Figure 3a shows an HR-TEM image of an isolated monocrystalline particle of size $23 \mathrm{~nm}$ obtained by fs laser irradiation. The distance between the crystallographic planes present in this NP was measured, giving a value of $2.46 \AA$ (inset), which can be indexed to the interplanar distance of the (111) family of planes in $\mathrm{Ag}^{0}$ with the typical fcc structure, in agreement with the JCPDS database (PDF04-0783). An important feature is the difference between this value and the one obtained when measuring the crystallographic plane spacing in the pure $\mathrm{Ag}^{0}$ sample prepared by fs irradiation of a $\mathrm{Ag}_{2} \mathrm{WO}_{4}$ target $(2.36 \AA$ for the (111) plane, a difference of about $+4.2 \%$, see Figure S3 in the SI), which agrees well with the reference data for this plane in $\mathrm{Ag}^{0}$. This behavior is related to an expansion of the fcc crystalline lattice of metallic $\mathrm{Ag}^{0}$ to accommodate Bi-substituting $\mathrm{Ag}$ atoms in the form of a randomly mixed pattern or solid solution (the atomic radii of $\mathrm{Ag}$ and $\mathrm{Bi}$ are 144 and $182 \mathrm{pm}$, respectively). ${ }^{47}$ Moreover, the measured interplanar spacing in the $\mathrm{Ag}-\mathrm{Bi}$ sample is very distinct from the values found for the orthorhombic crystalline

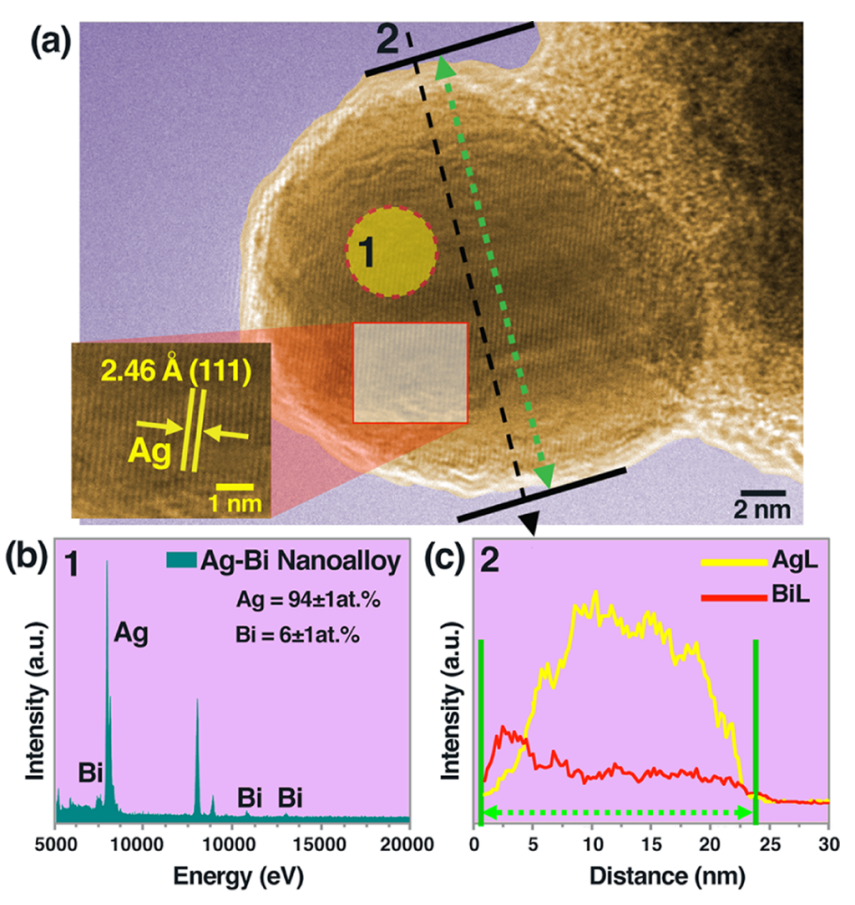

Figure 3. TEM characterization of a single Ag-Bi alloyed NP of size $23 \mathrm{~nm}$. (a) HR-TEM image, (b) local EDS analysis of region 1, and (c) line EDS analysis of region 2 .

structure of pure $\mathrm{Bi}^{0}$ obtained by irradiating a $\mathrm{NaBiO}_{3}$ target (see Figure S4 in the SI and the JCPDS database for this structure (44-12460)). This finding reinforces the conclusion that the Ag fcc structure was stabilized by the irradiation process in the $\mathrm{Ag}-\mathrm{Bi}$ sample with $\mathrm{Bi}$ atoms inserted into the lattice in a doping level. To confirm the $\mathrm{Ag}-\mathrm{Bi} \mathrm{NA}$ formation, an EDS study was performed. The local analysis in region 1 (dashed circle) is shown in Figure $3 \mathrm{~b}$ and confirms the major concentration of $\mathrm{Ag}$ element (94 \pm 1 atom \%), with the presence of Bi element at a doping level ( $6 \pm 1$ atom \%). This result also indicates that $\mathrm{Na}$ or $\mathrm{W}$ has negligible concentration 

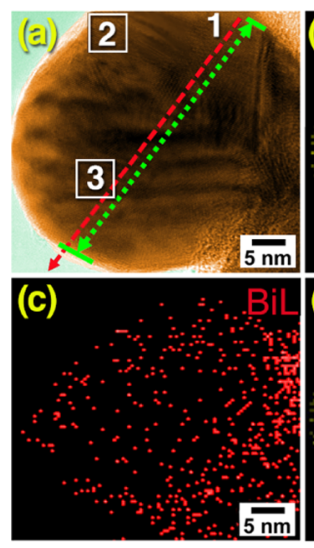

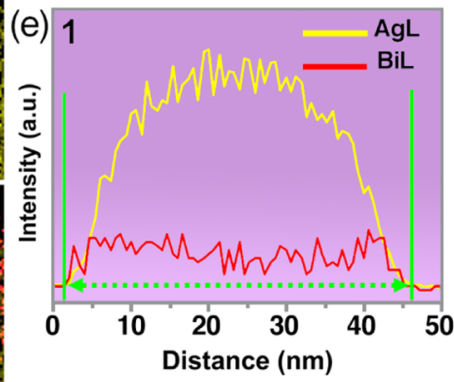

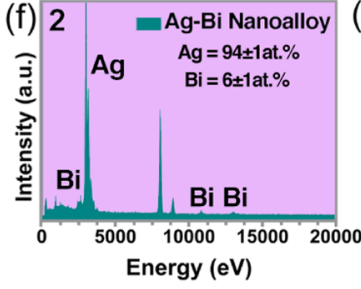

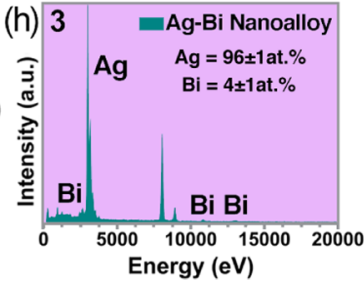

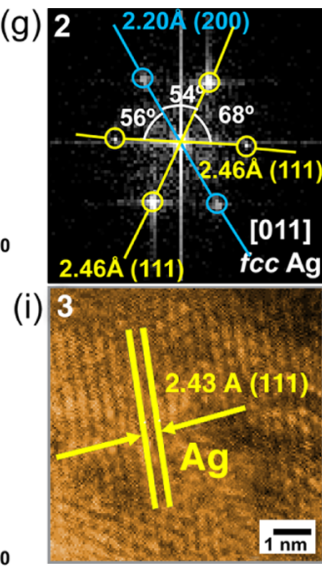

Figure 4. Insights into the formation of Ag-Bi NA. (a) HR-TEM images showing a monocrystalline Ag-Bi alloyed NP $43 \mathrm{~nm}$ in size, (b) AgL EDS map, (c) BiL EDS map, and (d) AgL-BiL overlaid EDS maps, and (e) line EDS profile of region 1. (f, g) Local quantification by EDS analysis and FFT of region 2 (NP border) and (h, i) local quantification by EDS analysis and HR-TEM images of region 3 (NP core).

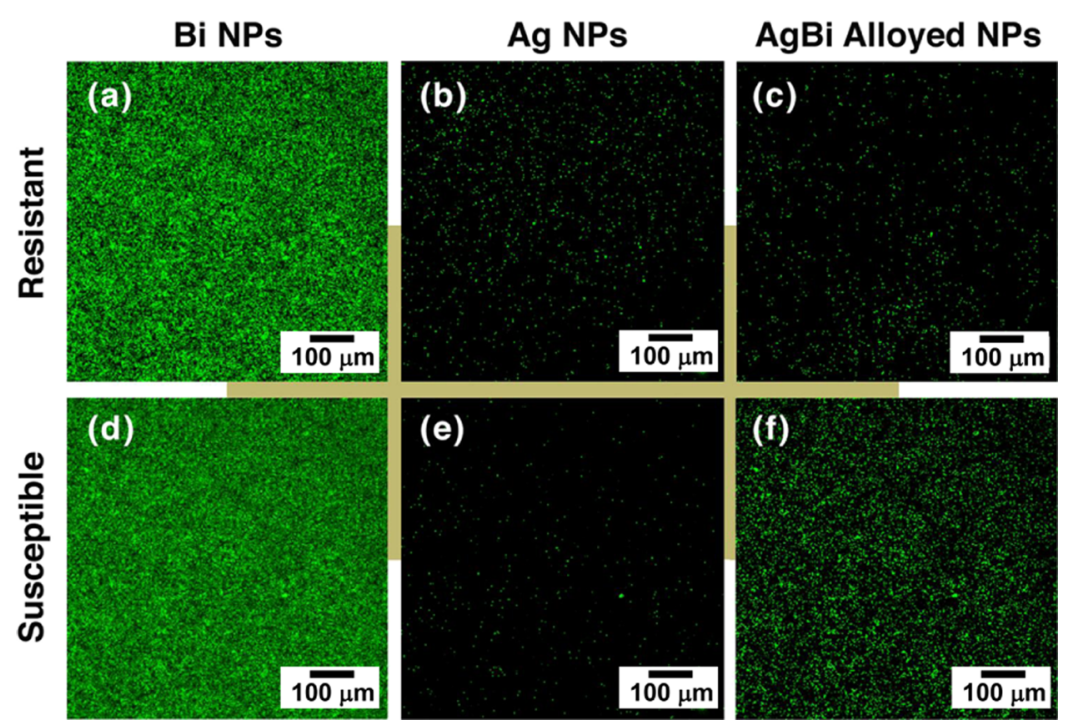

Figure 5. CLSM images of methicillin-resistant (top) and methicillin-susceptible (bottom) S. aureus cells treated with (a, d) Bi NPs, (b, e) Ag NPs, and (c, f) $\mathrm{Ag}-\mathrm{Bi} \mathrm{NA}$.

in NPs analyzed at the plasma plume. The EDS line analysis (black dashed line 2) shown in Figure $3 \mathrm{c}$ demonstrates the distribution of $\mathrm{Ag}$ and $\mathrm{Bi}$ elements along the NP (green dotted line), indicating a homogeneous insertion of $\mathrm{Bi}$ atoms in the $\mathrm{Ag}$ structure. The slightly higher concentration of $\mathrm{Bi}$ at the surface of the NP (see the red line of BiL signal at Figure 3c) is explained by the low miscibility between $\mathrm{Bi}$ and Ag. Therefore, a very thin layer was formed, richer in $\mathrm{Bi}$ than the core of the $\mathrm{Ag}-\mathrm{Bi}$ NP.

Figure 4a displays an HR-TEM image of a representative spot to gain a deeper insight into the $\mathrm{Ag}-\mathrm{Bi}$ NAs formed by fs irradiation. As the figure shows, a faceted well-crystallized single particle of size $43 \mathrm{~nm}$ was detected. A qualitative elemental distribution by EDS mapping was performed by using the characteristic L $\alpha$ lines of $\mathrm{Ag}$ and $\mathrm{Bi}$. These results demonstrated a distribution with a major concentration of $\mathrm{Ag}$ element (yellow dots, Figure 4b) and also, to a lesser extent, Bi element (red dots, Figure 4c). By overlaying these two individual maps (Figure 4d), we concluded that the Bi element is well distributed throughout the NA with a higher concentration at the surface compared to the core. The line
EDS analysis (red dashed line 1) of the $\mathrm{Ag} \mathrm{L} \alpha$ and $\mathrm{Bi} \mathrm{L} \alpha$ signals shown in Figure 4e also confirms the random mixture of $\mathrm{Bi}$ and $\mathrm{Ag}$ in the NA (green dotted line). The local EDS analysis in region 2, as illustrated in Figure 4f, indicates a composition of $94 \pm 1$ atom $\% \mathrm{Ag}$ and $6 \pm 1$ atom $\% \mathrm{Bi}$, which is similar to the composition of NP shown in Figure 3. To get a deeper understanding, a fast Fourier transform (FFT) of this same region was realized (Figure $4 \mathrm{~g}$ ). In this image, the typical pattern of a cubic structure along the [011] axis zone is observed, which undoubtedly confirms the fcc structure of Ag. The (200) and (111) planes of cubic $\mathrm{Ag}^{0}$ can be identified, in agreement with the JCPDS database (PDF04-0783), where an interplanar distance of $2.20 \AA$ is present for the former and $2.46 \AA$ for the latter family of planes. Again, these values are evidence of an expansion in the structure provoked by the inclusion of $\mathrm{Bi}$ into the lattice, which is reflected in the 7.8 and $4.2 \%$ expansions of the (200) and (111) planes (standard values are 2.04 and $2.36 \AA$ for (200) and (111), respectively). In addition, a change in the angles between these planes was detected, where a slight deviation of $1.8-3.0 \%$ is observed from the ideal values. The EDS analysis in region 3 at the core 
of the particle (Figure $4 \mathrm{~h}$ ) shows a slight decrease in the elemental percentage of $\mathrm{Bi}(96 \pm 1$ and $4 \pm 1$ atom $\%$ for $\mathrm{Ag}$ and $\mathrm{Bi}$, respectively). Moreover, as shown in the HR-TEM image shown in Figure 4i, the (111) interplanar distance has increased $(2.43 \AA$ ) compared to the reference value, but to a lesser extent than the value obtained at the border of the Ag$\mathrm{Bi}$ NA. These behaviors are associated with the tendency of $\mathrm{Bi}$ to be located more at the boundaries of the Ag-Bi NA.

The EDS analysis clearly shows the presence of Ag (94 \pm 1 to $96 \pm 1$ atom \%) and $\mathrm{Bi}(4 \pm 1$ to $6 \pm 1$ atom \%) at levels that indicate a higher miscibility of $\mathrm{Bi}$ in the $\mathrm{Ag}$ structure than that expected for $\mathrm{Ag}-\mathrm{Bi}$ systems. ${ }^{23}$ Moreover, despite the drawbacks predicted by the Hume-Rothery rules, ${ }^{24}$ the present results show that the high energy provided by fs laser irradiation is able to stabilize an NA composed of $\mathrm{Bi}$ atoms inserted into the cubic Ag structure.

In the present study, as a novel application of this NA, the bactericidal activities of $\mathrm{Bi}$ and $\mathrm{Ag}$ NPs as well as the $\mathrm{Ag}-\mathrm{Bi}$ NA were analyzed. In previous works, Ag-rich alloyed NPs, such as those containing $\mathrm{Au}, \mathrm{Cu}$, or $\mathrm{Pt}$, demonstrated superior bactericidal properties. ${ }^{4-50}$ Although recent studies have also shown that $\mathrm{Bi}$ inhibits some parasitic and microbial growth $^{51-53}$ and that the addition of $\mathrm{Bi}$ could modify the final properties of other alloys, ${ }^{5,55}$ to the best of our knowledge, the bactericidal activity of $\mathrm{Ag}-\mathrm{Bi}$ NAs has not been studied yet.

A strong inhibition of methicillin-resistant and methicillinsusceptible $S$. aureus bacteria (MRSA and MSSA, respectively) has been observed for both Ag NPs and Ag-Bi alloyed NPs. The minimum inhibitory concentration (MIC) found to be effective against MRSA was the same for both $\mathrm{Ag}^{0}$ and $\mathrm{Ag}-\mathrm{Bi}$ systems $(3.91 \mu \mathrm{g} / \mathrm{mL})$. For the susceptible strain, $\mathrm{Ag}^{0}(1.95$ $\mu \mathrm{g} / \mathrm{mL}$ ) was slightly more efficient than the Ag-Bi NA (3.91 $\mu \mathrm{g} / \mathrm{mL})$. Although $\mathrm{Bi}^{0} \mathrm{NPs}$ showed no antibacterial activity against any of the strains tested, when $\mathrm{Bi}$ atoms are associated with $\mathrm{Ag}$, an MIC similar to that of pure Ag NPs was found. Moreover, the $\mathrm{Ag}-\mathrm{Bi}$ system has a high antimicrobial efficiency compared to other Ag-rich alloys acting against similar microorganisms. ${ }^{56}$ Figure 5 shows the micrographs acquired by confocal laser scanning microscopy (CLSM) of living MSSA and MRSA cells treated with the fs laser-irradiated materials. It is possible to observe large numbers of living cells (green) when treated with Bi NPs (Figure 5a,d). On the other hand, significant reductions in the number of live cells were observed for both bacteria when treated with Ag NPs (Figure $5 b, e)$ and $\mathrm{Ag}-\mathrm{Bi}$ alloyed NPs (Figure 5c,f). Hence, Ag-Bi NA possesses high antibacterial activity, but the solubilization of $\mathrm{Bi}$ into the Ag structure did not cause significant differences in the antibacterial activity against MRSA and MSSA compared to pure $\mathrm{Ag}^{0}$, which supports the calculated MIC results. Ag NPs are known for their high antibacterial activity, but at certain concentrations, they are cytotoxic to human cells. ${ }^{57}$ In contrast, $\mathrm{Bi}$ is biocompatible and presents great potential in biomedical procedures, such as radiosensitizers in antitumor treatments. ${ }^{58}$ Thus, the high antibacterial activity of $\mathrm{Ag}-\mathrm{Bi}$ NA demonstrated in this work, combined with both the biological properties of $\mathrm{Bi}$ and the new possible properties arising from synergistic effects between $\mathrm{Ag}$ and $\mathrm{Bi}$ could be interesting for future technological and biomedical approaches. Hence, the results here have the potential to further increase the range of applicability of $\mathrm{Ag}-\mathrm{Bi}$ system alloyed at nanoscale.

In summary, bimetallic nanoalloys have abundant applications, but a thorough knowledge of the fundamentals of fs laser interactions with the target material is necessary to control their structure and properties. A new $\mathrm{Ag}-\mathrm{Bi}$ NA with high bactericidal activity was prepared by fs laser irradiation. TEM, HR-TEM, STEM, and EDS analyses (local, line, and mapping) demonstrated the insertion of $\mathrm{Bi}$ atoms into the fcc $\mathrm{Ag}$ structure at concentrations of up to $6 \pm 1$ atom $\%$ at the surface and $4 \pm 1$ atom $\%$ at the core of the alloyed NPs. The results presented here expand the fundamental understanding of the atomic processes, which underpin the mechanics of AgBi NA formation. Thus, the quantum phenomena associated with the fs irradiation, at the nanoscale, are able to minimize the difficulties involved in alloying metals that are very immiscible at the bulk scale, such as $\mathrm{Ag}$ and $\mathrm{Bi}$. It was found that alloying $\mathrm{Ag}$ and $\mathrm{Bi}$ at the atomic level leads to a high antibacterial activity against MSSA and MRSA cells (MIC = $3.91 \mu \mathrm{g} / \mathrm{mL}$ ). More broadly, this research introduces a new strategy for producing $\mathrm{Ag}-\mathrm{Bi}$ NAs using complex inorganic oxides as precursors as well as a new candidate in the pool of binary nanoalloys formed from elements that are immiscible at the bulk scale. It is anticipated that the obtained $\mathrm{Ag}-\mathrm{Bi}$ NAs will also find further applications as effective biomedical devices and catalysts.

\section{EXPERIMENTAL SECTION}

3.1. Materials. Sodium tungstate dihydrate $\left(\mathrm{Na}_{2} \mathrm{WO}_{4}\right.$. $2 \mathrm{H}_{2} \mathrm{O}, 99 \%$, Sigma-Aldrich), silver nitrate $\left(\mathrm{AgNO}_{3}, 99 \%\right.$, Sigma-Aldrich), and sodium bismuthate $\left(\mathrm{NaBiO}_{3}, 80 \%\right.$, AlfaAesar) were used as starting precursors.

3.2. Synthesis of $\boldsymbol{\alpha}-\mathrm{Ag}_{2} \mathrm{WO}_{4}$ Microrods. $\alpha-\mathrm{Ag}_{2} \mathrm{WO}_{4}$ powders were prepared in accordance with the procedure described by Longo et al. ${ }^{39}$ Briefly, $1.0 \mathrm{mmol}$ of $\mathrm{Na}_{2} \mathrm{WO}_{4}$. $2 \mathrm{H}_{2} \mathrm{O}$ and $2.0 \mathrm{mmol}$ of $\mathrm{AgNO}_{3}$ were dissolved separately in 50 $\mathrm{mL}$ of deionized water. Then, both the solutions were heated to $90{ }^{\circ} \mathrm{C}$ and kept under vigorous stirring. The $\mathrm{AgNO}_{3}$ solution was transferred into the other solution. Once the solutions were well mixed, the gray suspension thus formed was continuously stirred for $10 \mathrm{~min}$ at $90{ }^{\circ} \mathrm{C}$. The obtained crystals were allowed to precipitate at the bottom of the flask by turning off the magnetic stirring and naturally cooled to ambient temperature. The precipitate was separated by centrifugation and then washed with deionized water and acetone to remove any remaining impurities or reaction byproducts. The crystals were dried in an oven at $60{ }^{\circ} \mathrm{C}$ for 12 h.

3.3. Preparation of $\alpha-\mathrm{Ag}_{2} \mathrm{WO}_{4} / \mathrm{NaBiO}_{3}$. For the preparation of the $\alpha-\mathrm{Ag}_{2} \mathrm{WO}_{4} / \mathrm{NaBiO}_{3}$ precursor, the $\alpha-\mathrm{Ag}_{2} \mathrm{WO}_{4}$ powders previously synthesized by chemical precipitation were combined with a commercial $\mathrm{NaBiO}_{3}$ precursor by mechanical grinding. In this procedure, the $\alpha-\mathrm{Ag}_{2} \mathrm{WO}_{4}$ and $\mathrm{NaBiO}_{3}$ powders were homogeneously mixed in an agate mortar at a molar ratio of 50:50 and ground for $15 \mathrm{~min}$.

3.4. Synthesis of Ag-Bi Nanoalloys by Femtosecond Laser Irradiation. $\alpha-\mathrm{Ag}_{2} \mathrm{WO}_{4}, \mathrm{NaBiO}_{3}$, and $\mathrm{Ag}_{2} \mathrm{WO}_{4} /$ $\mathrm{NaBiO}_{3}$ powders were irradiated with a Ti:sapphire laser (Femtopower Compact Pro, Femto Lasers) using 30 fs full width at half-maximum (FWHM) pulses at a central wavelength of $800 \mathrm{~nm}$ and a repetition rate of $1 \mathrm{kHz}$. A laser beam with a mean power of $200 \mathrm{~mW}$ was focused onto the surface of the target powder with a spherical convex lens of $75 \mathrm{~mm}$ focal length to obtain a focal spot with a diameter of $20.6 \mu \mathrm{m}$ FWHM. The $\alpha-\mathrm{Ag}_{2} \mathrm{WO}_{4}, \mathrm{NaBiO}_{3}$, and $\mathrm{Ag}_{2} \mathrm{WO}_{4} /$ $\mathrm{NaBiO}_{3}$ samples were placed at the bottom of a quartz cuvette attached to a two-dimensional motion-controlled stage moving 
at a constant speed of $0.45 \mathrm{~mm} / \mathrm{s}$ in the focus plane perpendicular to the laser beam in a stairlike pattern. A programmable acousto-optic filter (Fazzler, Faslite) was utilized to obtain a more precise pulse compression at the target substrate. The monometallic and bimetallic alloyed NPs obtained in the plasma plume by irradiating the $\alpha-\mathrm{Ag}_{2} \mathrm{WO}_{4}$, $\mathrm{NaBiO}_{3}$, and $\alpha-\mathrm{Ag}_{2} \mathrm{WO}_{4} / \mathrm{NaBiO}_{3}$ targets were recovered for further morphological and structural characterization as well as to probe their biological activities.

3.5. Characterization. The samples were structurally characterized by X-ray diffraction in a Rigaku D/Max2500PC (Japan) diffractometer using $\mathrm{Cu} \mathrm{K} \alpha$ radiation $(\lambda=$ $0.15406 \mathrm{~nm})$. Data were collected over $2 \theta$ ranging from 20 to $70^{\circ}$, and at a step scan rate and step size of $1^{\circ} / \mathrm{min}$ and $0.02^{\circ}$, respectively. The morphological features were examined by field-emission scanning electron microscopy (FE-SEM) with a Carl Zeiss Supra 35-VP (Germany) microscope operated at 5 $\mathrm{kV}$. Transmission electron microscopy (TEM), high-resolution TEM (HR-TEM), energy-dispersive X-ray spectroscopy (EDS) analysis as well as scanning transmission electron microscopy (STEM) were performed with an FEI Tecnai F20 (The Netherlands) microscope operating at $200 \mathrm{kV}$. To analyze the metallic species readily formed in the plasma plume by electron microscopy, we recollected free-flying particles using a TEM grid before the formation of deposits in the bottom of the sample flask. This procedure avoids other variables in NPs characterization by TEM, such as the necessity of redispersion of NPs in a solvent to prepare the samples for analyses. It is important to mention that more than 10 HR-TEM images and EDS analyses of different zones of $\mathrm{Ag}-\mathrm{Bi} \mathrm{NPs}$ were realized during the EM characterization to describe the $\mathrm{Ag}-\mathrm{Bi}$ sample. Processing of the micrographs was carried out using DigitalMicrograph (Gatan) software. The dimensions of the nanoparticles were estimated using distinct TEM images collected from the irradiated sample and analyzed with ImageJ (NIH) software; the number of counts required for statistical analysis was 150 nanoparticles.

3.6. Bactericidal Activity. The microdilution method for planktonic cells was carried out to determine the minimum inhibitory concentration (MIC) against bacterial strains, according to Clinical Laboratory Standards Institute protocols with modifications. ${ }^{59}$ For bactericidal probes, the $\mathrm{Bi}, \mathrm{Ag}$, and $\mathrm{Ag}-\mathrm{Bi}$ NPs generated in the plasma plume were analyzed by recovering the particles allowed to settle down in the form of a thin layer at the bottom of the samples flasks. The $\mathrm{Bi}, \mathrm{Ag}$, and $\mathrm{Ag}-\mathrm{Bi}$ samples were resuspended in a sterile tryptic soy broth (TSB) culture medium at the required concentrations of $1000-0.49 \mu \mathrm{g} / \mathrm{mL}$, using the serial 2-fold dilution method. Standard strains of methicillin-resistant (MRSA) and methicillin-susceptible (MSSA) S. aureus from the American Type Culture Collection were used in this study. The microorganisms were stored at $-80{ }^{\circ} \mathrm{C}$ in TSB with glycerol prior to the experiments. Strains were plated on Mueller-Hinton agar plates and incubated at $37{ }^{\circ} \mathrm{C}$ for $24 \mathrm{~h}$. Then, MSSA and MRSA cells were grown in TSB up to the mid-exponential phase of growth. MICs were determined by incubating microorganisms on a 96-well microtiter plate exposed to serial dilution of the materials suspensions for $24 \mathrm{~h}$ at $37{ }^{\circ} \mathrm{C}$. The structural organization of the MSSA and MRSA culture cells treated by the nanoalloys was analyzed by laser scanning confocal microscopy. For this purpose, the bacteria cells were labeled with SYTO9 and propidium iodide (kit Live/Dead BacLight Molecular Probes Inc., Eugene, OR) after treatment with the nanoalloys. The confocal imaging was performed using a Carl Zeiss LSM 800 microscope.

\section{ASSOCIATED CONTENT}

\section{Supporting Information}

The Supporting Information is available free of charge on the ACS Publications website at DOI: 10.1021/acsomega.8b01264.

Characterization of precursor targets and $\mathrm{Ag}^{0}$ and $\mathrm{Bi}^{0}$ NPs (PDF)

\section{AUTHOR INFORMATION}

\section{Corresponding Author}

*E-mail: elson.liec@gmail.com.

ORCID ${ }^{\circ}$

Marcelo Assis: 0000-0003-0355-5565

Carlos Doñate-Buendia: 0000-0002-7022-0960

Camila C. Foggi: 0000-0002-1210-1234

Héctor Beltrán-Mir: 0000-0002-7836-1602

Juan Andrés: 0000-0003-0232-3957

Elson Longo: 0000-0001-8062-7791

\section{Author Contributions}

The manuscript was written through contributions of all authors. All authors have given approval to the final version of the manuscript.

Notes

The authors declare no competing financial interest.

\section{ACKNOWLEDGMENTS}

The authors are grateful to CAPES/PNPD, CEPID-FAPESP (2013/07296-2), FAPESP (2017/12594-3), CNPq (150205/ 2017-1), Ministerio de Economia y Competitividad (MAT2016-80410-P, FIS2016-75618-R and CTQ201565207-P), Universitat Jaume I (UJI-B2016-38 and UJIB2016-25), Generalitat Valenciana (PROMETEU/2016/079 and $A C O M P / 2015 / 1202$ ) for the financial support. The authors are also very grateful to the Serveis Centrals d'Instrumentació Cientifica (SCIC) of the University Jaume I for the use of the femtosecond laser and microscopy facilities. Special thanks go to Dr. Said Agouram, Rorivaldo Camargo, and João P. C. Costa for their scientific and technical support. The authors also thank Enio Longo for design contributions.

\section{REFERENCES}

(1) Jellinek, J. Nanoalloys: Tuning Properties and Characteristics through Size and Composition. Faraday Discuss. 2008, 138, 11-35.

(2) Ferrando, R.; Jellinek, J.; Johnston, R. L. Nanoalloys: From Theory to Applications of Alloy Clusters and Nanoparticles. Chem. Rev. 2008, 108, 845-910.

(3) Singh, A. K.; Xu, Q. Synergistic Catalysis over Bimetallic Alloy Nanoparticles. ChemCatChem 2013, 5, 652-676.

(4) Shi, J. On the Synergetic Catalytic Effect in Heterogeneous Nanocomposite Catalysts. Chem. Rev. 2013, 113, 2139-2181.

(5) Mun, J. H.; Chang, Y. H.; Shin, D. O.; Yoon, J. M.; Choi, D. S.; Lee, K. M.; Kim, J. Y.; Cha, S. K.; Lee, J. Y.; Jeong, J. R.; et al. Monodisperse Pattern Nanoalloying for Synergistic Intermetallic Catalysis. Nano Lett. 2013, 13, 5720-5726.

(6) Pang, H.; Gallou, F.; Sohn, H.; Camacho-Bunquin, J.; Delferro, M.; Lipshutz, B. H. Synergistic Effects in Fe Nanoparticles Doped with ppm Levels of $(\mathrm{Pd}+\mathrm{Ni})$. A New Catalyst for Sustainable Nitro Group Reductions. Green Chem. 2018, 20, 130-135. 
(7) Cabrero-Antonino, J. R.; Tejeda-Serrano, M.; Quesada, M.; Vidal-Moya, J. A.; Leyva-Pérez, A.; Corma, A. Bimetallic Nanosized Solids with Acid and Redox Properties for Catalytic Activation of C$\mathrm{C}$ and C-H Bonds. Chem. Sci. 2017, 8, 689-696.

(8) Yu, F.; Zhou, W.; Bellabarba, R. M.; Tooze, R. P. One-Step Synthesis and Shape-Control of CuPd Nanowire Networks. Nanoscale 2014, 6, 1093-1098.

(9) Zhang, H.; Son, J. S.; Jang, J.; Lee, J. S.; Ong, W. L.; Malen, J. A.; Talapin, D. V. Bi $i_{1-x} S b_{x}$ Alloy Nanocrystals: Colloidal Synthesis, Charge Transport, and Thermoelectric Properties. ACS Nano 2013, 7, 10296-10306.

(10) Yamauchi, M.; Okubo, K.; Tsukuda, T.; Kato, K.; Takata, M.; Takeda, S. Hydrogen-Induced Structural Transformation of $\mathrm{AuCu}$ Nanoalloys Probed by Synchrotron X-Ray Diffraction Techniques. Nanoscale 2014, 6, 4067-4071.

(11) Coq, B.; Figueras, F. Bimetallic Palladium Catalysts: Influence of the Co-Metal on the Catalyst Performance. J. Mol. Catal. A: Chem. 2001, 173, 117-134.

(12) Gaudry, M.; Cottancin, E.; Pellarin, M.; Lermé, J.; Arnaud, L.; Huntzinger, J. R.; Vialle, J. L.; Broyer, M.; Rousset, J. L.; Treilleux, M.; et al. Size and Composition Dependence in the Optical Properties of Mixed (Transition Metal/noble Metal) Embedded Clusters. Phys. Rev. B 2003, 67, No. 155409.

(13) Paulus, U. A.; Wokaun, A.; Scherer, G. G.; Schmidt, T. J.; Stamenkovic, V.; Radmilovic, V.; Markovic, N. M.; Ross, P. N. Oxygen Reduction on Carbon-Supported Pt-Ni and Pt-Co Alloy Catalysts. J. Phys. Chem. B 2002, 106, 4181-4191.

(14) Son, S. U.; Jang, Y.; Park, J.; Na, H.; Park, H. M.; Yun, H. J.; Lee, J.; Hyeon, T. Designed Synthesis of Atom-Economical Pd/Ni Bimetallic Nanoparticle-Based Catalysts for Sonogashira Coupling Reactions. J. Am. Chem. Soc. 2004, 126, 5026-5027.

(15) Cao, Y.; Jin, R.; Mirkin, C. A. DNA-Modified Core-Shell Ag/ Au Nanoparticles. J. Am. Chem. Soc. 2001, 123, 7961-7962.

(16) Guo, S.; Wang, E. Functional Micro/nanostructures: Simple Synthesis and Application in Sensors, Fuel Cells, and Gene Delivery. Acc. Chem. Res. 2011, 44, 491-500.

(17) Burda, C.; Chen, X.; Narayanan, R.; El-Sayed, M. A. Chemistry and Properties of Nanocrystals of Different Shapes. Chem. Rev. 2005, $105,1025-1102$.

(18) Ferrando, R. Structure and Properties of Nanoalloys; Elsevier: Amsterdam, 2016.

(19) Christensen, A.; Stoltze, P.; Norskov, J. K. Size Dependence of Phase Separation in Small Bimetallic Clusters. J. Phys.: Condens. Matter 1995, 7, 1047-1057.

(20) Toshima, N.; Wang, Y. Preparation and Catalysis of Novel Colloidal Dispersions of Copper/Noble Metal Bimetallic Clusters. Langmuir 1994, 10, 4574-4580.

(21) Zlotea, C.; Morfin, F.; Nguyen, T. S.; Nguyen, N. T.; Nelayah, J.; Ricolleau, C.; Latroche, M.; Piccolo, L. Nanoalloying BulkImmiscible Iridium and Palladium Inhibits Hydride Formation and Promotes Catalytic Performances. Nanoscale 2014, 6, 9955-9959.

(22) Digges, T. G.; Tauber, R. N. Structure of Bi-Ag Eutectic Alloy. J. Cryst. Growth 1971, 8, 132-134.

(23) Karakaya, I.; Thompson, W. T. The Ag-Bi (Silver-Bismuth) System. J. Phase Equilib. 1993, 14, 525-530.

(24) Hume-Rothery, W.; Haworth, C. W.; Smallman, R. E. The Structure of Metals and Alloys; Institute of Metals and the Institution of Metallurgists: London, 1969

(25) Jiao, Z.; Zhang, Y.; Ouyang, S.; Yu, H.; Lu, G.; Ye, J.; Bi, Y. BiAg Alloy Nanospheres: A New Photocatalyst for $\mathrm{H}_{2}$ Evolution from Water Splitting. ACS Appl. Mater. Interfaces 2014, 6, 19488-19493.

(26) Gong, J.; Lee, C.; Chang, Y.; Chang, Y. A Novel SelfAssembling Nanoparticle of $\mathrm{Ag}-\mathrm{Bi}$ with High Reactive Efficiency. Chem. Commun. 2014, 50, 8597-8600.

(27) Ruiz-Ruiz, V.-F.; Zumeta-Dubé, I.; Díaz, D.; Arellano-Jiménez, M. J.; José-Yacamán, M. Can Silver Be Alloyed with Bismuth on Nanoscale? An Optical and Structural Approach. J. Phys. Chem. C 2017, 121, 940-949.
(28) Vorobyev, A. Y.; Guo, C. Direct Femtosecond Laser Surface Nano/microstructuring and Its Applications. Laser Photonics Rev. 2013, 7, 385-407.

(29) Xiong, W.; Zhou, Y.; Hou, W.; Jiang, L.; Mahjouri-Samani, M.; Park, J.; He, X.; Gao, Y.; Fan, L.; Baldacchini, T.; et al. Laser-Based Micro/nanofabrication in One, Two and Three Dimensions. Front. Optoelectron. 2015, 8, 351-378.

(30) Tan, D.; Zhou, S.; Qiu, J.; Khusro, N. Preparation of Functional Nanomaterials with Femtosecond Laser Ablation in Solution. J. Photochem. Photobiol., C 2013, 17, 50-68.

(31) Nandini, P.; Akash, K.; Rohit, G.; Vipul, S.; Palani, I. A. Investigations on the Influence of Liquid-Assisted Laser Ablation of NiTi Rotating Target to Improve the Formation Efficiency of Spherical Alloyed NiTi Nanoparticles. J. Mater. Eng. Perform. 2017, 26, 4707-4717.

(32) Chen, Q.; Song, H.; Zhang, F.; Zhang, H.; Yu, Y.; Chen, Z.; Wei, R.; Dai, Y.; Qiu, J. A Strategy for Fabrication of Controllable 3D Pattern Containing Clusters and Nanoparticles inside a Solid Material. Nanoscale 2017, 9, 9083-9088.

(33) Fujita, Y.; Aubert, R.; Walke, P.; Yuan, H.; Kenens, B.; Inose, T.; Steuwe, C.; Toyouchi, S.; Fortuni, B.; Chamtouri, M.; et al. Highly Controllable Direct Femtosecond Laser Writing of Gold Nanostructures on Titanium Dioxide Surfaces. Nanoscale 2017, 9, 1302513033.

(34) Sarker, M. S. I.; Nakamura, T.; Herbani, Y.; Sato, S. Fabrication of Rh Based Solid-Solution Bimetallic Alloy Nanoparticles with FullyTunable Composition through Femtosecond Laser Irradiation in Aqueous Solution. Appl. Phys. A: Mater. Sci. Process. 2013, 110, 145152.

(35) Assis, M.; Cordoncillo, E.; Torres-Mendieta, R.; Beltrán-Mir, H.; Mínguez-Vega, G.; Oliveira, R.; Leite, E. R.; Foggi, C. C.; Vergani, C. E.; Longo, E.; et al. Towards Scale-up the Formation of Nanoparticles on $\alpha-\mathrm{Ag}_{2} \mathrm{WO}_{4}$ with Bactericide Properties by Femtosecond Laser Irradiation. Sci. Rep. 2018, 8, No. 1884.

(36) Chau, J. L. H.; Chen, C. Y.; Yang, C. C. Facile Synthesis of Bimetallic Nanoparticles by Femtosecond Laser Irradiation Method. Arabian J. Chem. 2017, 10, S1395-S1401.

(37) Zhang, D.; Gökce, B.; Barcikowski, S. Laser Synthesis and Processing of Colloids: Fundamentals and Applications. Chem. Rev. 2017, 117, 3990-4103.

(38) Longo, V. M.; Foggi, C.; Ferrer, M. M.; Gouveia, A. F.; André, R. S.; Avansi, W.; Vergani, C. E.; Machado, A. L.; Andrés, J.; Hernandes, A. C.; et al. Potentiated Electron Transference in $\alpha$ $\mathrm{Ag}_{2} \mathrm{WO}_{4}$ Microcrystals with Ag Nanofilaments as Microbial Agent. J. Phys. Chem. A 2014, 118, 5769-5778.

(39) Longo, E.; Volanti, D. P.; Longo, V. M.; Gracia, L.; Nogueira, I. C.; Almdeira, M. A. P.; Pinheiro, A. N.; Ferrer, M. M.; Cavalcante, L. S.; Andrés, J. Toward an Understanding of the Growth of $\mathrm{Ag}$ Filaments on $\alpha-\mathrm{Ag}_{2} \mathrm{WO}_{4}$ and Their Photoluminescent Properties: A Combined Experimental and Theoretical Study. J. Phys. Chem. C 2014, 118, 1229-1239.

(40) de Oliveira, R. C.; Zanetti, S. M.; Assis, M.; Penha, M.; Mondego, M.; Cilense, M.; Longo, E.; Cavalcante, L. S. Effect of Metallic Ag Growth on the Electrical Resistance of 3D Flower-like $\mathrm{Ag}_{4} \mathrm{~V}_{2} \mathrm{O}_{7}$ Crystals. J. Am. Ceram. Soc. 2017, 100, 2358-2362.

(41) Longo, E.; Cavalcante, L. S.; Volanti, D. P.; Gouveia, A. F.; Longo, V. M.; Varela, J. A.; Orlandi, M. O.; Andrés, J. Direct in Situ Observation of the Electron-Driven Synthesis of Ag Filaments on $\alpha$ $\mathrm{Ag}_{2} \mathrm{WO}_{4}$ Crystals. Sci. Rep. 2013, 3, No. 1676.

(42) Andrés, J.; Gracia, L.; Gonzalez-Navarrete, P.; Longo, V. M.; Avansi, W. J.; Volanti, D. P.; Ferrer, M. M.; Lemos, P. S.; La Porta, F. A.; Hernandes, A. C.; et al. Structural and Electronic Analysis of the Atomic Scale Nucleation of $\mathrm{Ag}$ on $\alpha-\mathrm{Ag}_{2} \mathrm{WO}_{4}$ Induced by Electron Irradiation. Sci. Rep. 2014, 4, No. 5391.

(43) Longo, E.; Avansi, W. J.; Bettini, J.; Andrés, J.; Gracia, L. In Situ Transmission Electron Microscopy Observation of Ag Nanocrystal Evolution by Surfactant Free Electron-Driven Synthesis. Sci. Rep. 2016, 6, No. 21498. 
(44) San-Miguel, M. A.; da Silva, E. Z.; Zanetti, S. M.; Cilense, M.; Fabbro, M. T.; Gracia, L.; Andrés, J.; Longo, E. In Situ Growth of Ag Nanoparticles on $\alpha-\mathrm{Ag}_{2} \mathrm{WO}_{4}$ under Electron Irradiation: Probing the Physical Principles. Nanotechnology 2016, 27, No. 225703.

(45) Fabbro, M. T.; Gracia, L.; Silva, G. S.; Santos, L. P. S.; Andrés, J.; Cordoncillo, E.; Longo, E. Understanding the Formation and Growth of Ag Nanoparticles on Silver Chromate Induced by Electron Irradiation in Electron Microscope: A Combined Experimental and Theoretical Study. J. Solid State Chem. 2016, 239, 220-227.

(46) Assis, M.; Cordoncillo, E.; Torres-Mendieta, R.; Beltrán-Mir, H.; Minguez-Vega, G.; Gouveia, A. F.; Leite, E.; Andrés, J.; Longo, E. Laser-Induced Formation of Bismuth Nanoparticles. Phys. Chem. Chem. Phys. 2018, 13693-13696.

(47) Wells, A. F. Structural Inorganic Chemistry; Clarendon Press: Oxford, 1984.

(48) Hu, X.; Zhao, Y.; Hu, Z.; Saran, A.; Hou, S.; Wen, T.; Liu, W.; Ji, Y.; Jiang, X.; Wu, X. Gold Nanorods core/AgPt Alloy Nanodots Shell: A Novel Potent Antibacterial Nanostructure. Nano Res. 2013, 6, 822-835.

(49) Paszkiewicz, M.; Gołąbiewska, A.; Rajski, Ł.; Kowal, E.; Sajdak, A.; Zaleska-Medynska, A. Synthesis and Characterization of Monometallic ( $\mathrm{Ag}, \mathrm{Cu}$ ) and Bimetallic $\mathrm{Ag}-\mathrm{Cu}$ Particles for Antibacterial and Antifungal Applications. J. Nanomater. 2016, 2016, No. 2187940.

(50) Padmos, J. D.; Langman, M.; Macdonald, K.; Comeau, P.; Yang, Z.; Filiaggi, M.; Zhang, P. Correlating the Atomic Structure of Bimetallic Silver Gold Nanoparticles to Their Antibacterial and Cytotoxic Activities. J. Phys. Chem. C 2015, 119, 7472-7482.

(51) Rodríguez-Luis, O. E.; Hernández-Delgadillo, R.; PinedaAguilar, N.; Vargas-Villarreal, J.; González-Salazar, F.; GarzaGonzález, J. N.; Hernández-García, M. E.; Chellam, S.; CabralRomero, C. Effect of Bismuth Lipophilic Nanoparticles (BisBAL NPs) on Trichomonas vaginalis Growth. J. Nanosci. Nanotechnol. 2016, 16, $1-5$.

(52) Badireddy, A. R.; Hernandez-Delgadillo, R.; Sánchez-Nájera, R. I.; Chellam, S.; Cabral-Romero, C. Synthesis and Characterization of Lipophilic Bismuth Dimercaptopropanol Nanoparticles and Their Effects on Oral Microorganisms Growth and Biofilm Formation. J. Nanopart. Res. 2014, 16, No. 2456.

(53) Hernandez-Delgadillo, R.; Del Angel-Mosqueda, C.; Solís-Soto, J. M.; Munguia-Moreno, S.; Pineda-Aguilar, N.; Sánchez-Nájera, R. I.; Chellam, S.; Cabral-Romero, C. Antimicrobial and Antibiofilm Activities of MTA Supplemented with Bismuth Lipophilic Nanoparticles. Dent. Mater. J. 2017, 36, 503-510.

(54) Gandhi, A. C.; Wu, S. Y. Routes to Probe Bismuth Induced Strong-Coupling Superconductivity in Bimetallic BiIn Alloys. Sci. Rep. 2017, 7, No. 9442.

(55) Polak, M. P.; Scharoch, P.; Kudrawiec, R. First-Principles Calculations of Bismuth Induced Changes in the Band Structure of Dilute Ga-V-Bi and In-V-Bi Alloys: Chemical Trends versus Experimental Data. Semicond. Sci. Technol. 2015, 30, No. 094001.

(56) Grade, S.; Eberhard, J.; Jakobi, J.; Winkel, A.; Stiesch, M.; Barcikowski, S. Alloying Colloidal Silver Nanoparticles with Gold Disproportionally Controls Antibacterial and Toxic Effects. Gold Bull. 2014, 47, 83-93.

(57) Franci, G.; Falanga, A.; Galdiero, S.; Palomba, L.; Rai, M.; Morelli, G.; Galdiero, M. Silver Nanoparticles as Potential Antibacterial Agents. Molecules 2015, 20, 8856-8874.

(58) Deng, J.; Xu, S.; Hu, W.; Xun, X.; Zheng, L.; Su, M. Tumor Targeted, Stealthy and Degradable Bismuth Nanoparticles for Enhanced X-Ray Radiation Therapy of Breast Cancer. Biomaterials 2018, 154, 24-33.

(59) Clinical and Laboratory Standards Institute (CLSI). M27-A: Performance Standards for Antimicrobial Susceptibility Testing; CLSI: Villanova, PA, 1997. 